\title{
Migrant Domestic Workers' Experiences of Sexual Harassment: A Qualitative Study in Four EU Countries
}

\author{
Maria Papadakaki ${ }^{1, *(0)}$, Nikoleta Ratsika ${ }^{1}$, Lina Pelekidou ${ }^{1}$, Brigitte Halbmayr ${ }^{2}$, Christiana Kouta ${ }^{3}$, \\ Katrin Lainpelto ${ }^{4}$, Miran Solinc ${ }^{5}$, Zoe Apostolidou ${ }^{3}$, Josie Christodoulou ${ }^{6}$, Andrej Kohont ${ }^{5}$, Jack Lainpelto ${ }^{4}$, \\ Christalla Pithara ${ }^{7,8}\left(\mathbb{D}\right.$, Anna Zobnina ${ }^{6}$ and Joannes Chliaoutakis ${ }^{1}$
}

check for updates

Citation: Papadakaki, M.; Ratsika, N.; Pelekidou, L.; Halbmayr, B.; Kouta, C.; Lainpelto, K.; Solinc, M.; Apostolidou, Z.; Christodoulou, J.; Kohont, A.; et al. Migrant Domestic Workers' Experiences of Sexual Harassment: A Qualitative Study in Four EU Countries. Sexes 2021, 2 , 272-292. https://doi.org/10.3390/ sexes 2030022

Academic Editor: Sally Guttmacher

Received: 16 May 2021

Accepted: 23 June 2021

Published: 1 July 2021

Publisher's Note: MDPI stays neutral with regard to jurisdictional claims in published maps and institutional affiliations.

Copyright: (c) 2021 by the authors. Licensee MDPI, Basel, Switzerland. This article is an open access article distributed under the terms and conditions of the Creative Commons Attribution (CC BY) license (https:// creativecommons.org/licenses/by/ $4.0 /)$.
1 Department of Social Work, School of Health Sciences, Hellenic Mediterranean University, 71004 Heraklion Crete, Greece; ratsika@hmu.gr (N.R.); pelekidou@hmu.gr (L.P.); jchlia@hmu.gr (J.C.)

2 Institute of Conflict Research, A-1030 Vienna, Austria; brigitte.halbmayr@ikf.ac.at

3 Department of Nursing, School of Health Sciences, Cyprus University of Technology, 3036 Limassol, Cyprus; Christiana.kouta@cut.ac.cy (C.K.); zoechristina@hotmail.com (Z.A.)

4 Juridiska Institutionen, Stockholms Universitet, 10691 Stockholm, Sweden; katrin.lainpelto@juridicum.su.se (K.L.); jack.lainpelto@oru.se (J.L.)

5 Faculty of Social Sciences, University of Ljubljana, 1000 Ljubljana, Slovenia; miran.solinc@amis.net (M.S.); andrej.kohont@fdv.uni-lj.si (A.K.)

6 Mediterranean Institute of Gender Studies, 1703 Nicosia, Cyprus; josie@medinstgenderstudies.org (J.C.); zobnina.a@medinstgenderstudies.org (A.Z.)

7 Population Health Sciences, Bristol Medical School, University of Bristol, Bristol BS8 1QU, UK; christalla.pithara@bristol.ac.uk

8 National Institute for Health Research Applied Research Collaboration West, University Hospitals Bristol and Weston Foundation Trust, Bristol BS1 2NT, UK

* Correspondence: mpapadakaki@yahoo.gr

Abstract: Sexual harassment against female migrant domestic workers is a public health problem, which remains hidden and largely underreported. The current paper presents the results of a qualitative research study on sexually victimized migrant domestic workers in four European countries (Austria, Cyprus, Greece, and Sweden). The study aimed at exploring the profile and experiences of victimised individuals. Data were gathered via 66 semi-structured interviews with victimised female migrant domestic workers. Key findings of the current study indicate that the victims: (a) were usually undocumented and had low local language skills; (b) identified domestic work as the only way into the labour market; (c) suffered primarily psychological, economic, and social consequences; (d) had poor social support networks; (e) were poorly connected to governmental support services. This is the first study to explore this hidden problem via direct contact with victims. Addressing barriers of migrants' social integration seems important. Better regulation and monitoring of this low-skilled occupation could minimise risks for vulnerable employees.

Keywords: domestic worker; migrant; undocumented; sexual harassment; violence; social network

\section{Introduction}

Sexual harassment against domestic workers is seen as an illegal and unacceptable phenomenon that is embedded in the patterns of society [1]. There are structural issues regarding this occupational group, which seem to increase their vulnerability to sexual exploitation. Firstly, the domestic sector has lower language and educational requirements, with low-status, low-skilled, and low-paid jobs. Secondly, demand for such work is usually driven by the employer. Thirdly, domestic work takes place in the private household away from the outside world and the scrutiny of regulatory bodies [1-4].

Migrants seem to be in an even more disadvantageous position as compared with local workers for various reasons. First, the dependence on employers for obtaining and retaining employment or work permits might facilitate exploitation especially in the case of 
undocumented migrants [2,5]. Second, the social, cultural, and linguistic barriers faced by migrant domestic workers and the limited knowledge of legislation seem to increase their vulnerability to sexual exploitation $[5,6]$. In fact, undocumented migrant domestic workers without permits are thought to be the most isolated and therefore the most vulnerable of all workers, excluded from social rights and access to formalized labor market relations and living a precarious existence, often institutionalized in legal, social, cultural, and economic apartheids [7]. It has been shown to be common for this group of migrants not to know their rights and therefore to become more vulnerable to abuse. In particular, in many cases, they seem to rely either on their employers and agencies or on their husbands or male relatives to receive information on their rights [8]. Third, migrant domestic workers have been shown to be more vulnerable to exploitation than others due to lacking infrastructure and resources [8,9], as well as due to lacking trade unions, guidelines, and information from authorities [9]. Restricted access to resources has also been linked with migrant domestic workers' reluctance to report incidents of abuse and other human rights' violations to law enforcement agencies due to fear of deportation [8].

Given the composition of the domestic workforce, women seem to be disproportionately affected. In fact, women have been noted to become suitable targets in the proximity of motivated offenders, especially when placed in a subordinate role such as in the domestic sector [4]. Gender-based cultural assumptions that often legitimize unwanted sexual advances towards females has been shown to intersect with various other vulnerabilities, including their legal and the financial status [1].

Despite the aforementioned susceptibility to "abuse" of this occupational group of female workers, the severe health and mental health consequences on victims and the overall costs for health systems and national economies, prevention and management of the phenomenon is still problematic [1,2]. Monitoring is still missing and this affects the quality and effectiveness of interventions. Moreover, research in this area seems to be neglected and therefore many aspects of the phenomenon remain hidden [1]. The need to strengthen the knowledge base on sexual violence against migrant domestic workers, through rigorous research and efficient monitoring of the problem, has been identified as a pressing gap [2].

Most importantly, in light of the demographic changes and the increase of the ageing population, the demand in domestic work services is expected to grow rapidly and governments are already urged to take action towards safeguarding workers' rights against abusive situations $[1,2]$. In this respect, promoting the voice of migrant domestic workers and reflecting their individual needs in policy making is highly warranted [1].

The current study is part of a European project "Commun-AID—Increasing the capacity of domestic workers of different origins to respond to sexual violence through community-based interventions" funded by European Commission under the DAPHNE III programme (JUST/2011/DAP/AG/3272). The study aimed to describe this underinvestigated phenomenon through exploring the experiences of sexually victimized female migrant domestic workers. It further aimed to give an insight of the barriers faced by the victims in seeking help as well as the policy gaps in effective management of the problem in the four countries. This is one of the few existing studies employing face-to-face interview techniques in the exploration of experiences of sexual victimization in this hard-to-reach female migrant population.

For comparative purposes, the study sites included countries from south, central, and north Europe with high migrant flows and migrant domestic workforce as well as with diverse regulatory framework and policies regarding domestic work. Interestingly, the study involves countries with a different gender equality index in Europe during 2020, including the lowest (Greece) and the highest across Europe (Sweden). This will help us gain a better understanding of the impact of gender employment gap and female labour participation on female sexual victimisation at work.

The study comes in a "difficult" period for migrant domestic workers due to the recent circumstances, namely the impact of the world financial crisis and the recent COVID-19 
pandemic, which are adding new pressures to this occupational group in Europe [1]. In light of the aforementioned circumstances, the current study comes in a timely manner to generate evidence and open new channels in the investigation of this difficult to study problem in countries with a high migration influx. The study aims at generating information on the individual characteristics of the victims in each of the four countries as well as running comparisons among these countries that present great differences in terms of domestic work regulation. In particular, the study aims to answer the following research questions: What are the victims' sociodemographic and occupational profiles? What are the victims' experiences of sexual harassment at work? How does this phenomenon affect the victims' personal life and occupation? How do the victims cope with this problem and what barriers do they experience in efficiently addressing the problem?

\section{Materials and Methods}

\subsection{Study Design}

The overall approach was a qualitative inquiry consisting of four field research studies (Austria, Cyprus, Greece, Sweden). Qualitative methods allowed us to gain initial knowledge of the phenomenon, since the existing literature is limited. Semi-structured interviews were employed for data collection as they allowed us to yield rich sources of data on people's experiences, opinions, aspirations, and feelings as well as to securely explore certain themes while allowing unexpected information to occur [10]. For the needs of the study, we adopted the following definition of sexual harassment from the Istanbul Convention of the Council of Europe: "any form of unwanted verbal, non-verbal or physical conduct of a sexual nature with the purpose or effect of violating the dignity of a person, in particular when creating an intimidating, hostile, degrading, humiliating or offensive environment" [11]. Verbal, non-verbal, and physical harassment examples were also identified to guide the research, e.g., asking personal questions about someone's social or sex life, making sexual comments about clothing, or looks, repeatedly trying to date a person who is not interested, looking a person up and down, using sexually suggestive visuals, making sexual gestures with the hands or through body movements, touching another person's clothing, hair, or body, hugging, kissing, etc.

\subsection{Participant Recruitment}

Participants were recruited in all the four study sites. To be eligible for participation in the study, subjects had to fulfill the following criteria: (a) be women, (b) be migrants (regardless of ethnicity), (c) work as domestic workers, (d) be victims of sexual violence or harassment at domestic work (currently or in the past), and (e) possess basic skills in the local language. A snowball technique was employed for participants' recruitment as the most appropriate technique for populations that are difficult to reach. Participants were initially drawn from community organizations and social services offering support or accommodation to victimized women, community leaders, community groups, NGOs, or other organisations linked to migrant women and domestic workers. Furthermore, advertisements were placed in newspapers and websites, while labour market organizations were also contacted. No compensation was offered for participation in the study. Refusals ranged from 0 to 2 cases per country.

\subsection{Interview Guide}

An interview guide was developed to serve the data collection process (Appendix A). The guide ensured that all the necessary information would be collected, rather than a schema, which would be followed strictly. The guide also allowed flexibility on capturing any unexpected information as well as ensuring that all interviews had a conversational style while focusing on the predetermined thematic areas. It included 6 main thematic areas as follows: (a) working conditions, (b) encounters of sexual violence/harassment, (c) perpetrator(s)' characteristics, (d) responses to sexual violence/harassment, (e) consequences of sexual violence/harassment, (f) perceived needs for support. Participant 
socio-demographic data were also collected at the time of the interview using a structured questionnaire (Appendix B).

\subsection{Procedures}

Face-to-face and/or telephone interviews were conducted with the study participants. Researchers in each country contacted potential participants by phone or in person to arrange the date and time of the interview. Interviews were conducted in the local language and had a duration of 60-120 min. No interpreters were employed in the data collection process since eligibility criteria for participation in the study required participants to possess basic skills in the local language. The interviews were conducted at places familiar to the interviewees in order to ensure that they felt comfortable and secure. Coffee or tea during the interview was offered. The interview was tape-recorded upon the participants' consent. An interview record with basic information was completed in each study site.

In regards to ethical clearance, certain prerequisites were anticipated in order to safeguard participants' dignity, safety, and autonomy. This is of utmost importance for individuals who experience multiple vulnerabilities, such as in our study population.

Firstly, recruitment of participants was carried out at a voluntary basis in order to ensure sufficient autonomy throughout the research process. Secondly, informed consent was granted prior to participation with all the information offered written in the mother language of the participants. Thirdly, maintenance of confidentiality was an important ethical issue in this study. For that reason, data coding and reduction of personal identifiers proved to be valuable in safeguarding participants' anonymity. Fourthly, concern was raised about the potential harm generated by the research process itself. For instance, viewing an email could make their participation more hazardous and place them at risk from family members. In this respect, we offered participants the option to select the means of communication and the place of the interview. Lastly, disclosure of violence could result in recalling unpleasant experiences, re-experiencing negative emotions, and re-traumatization. Participants were thus reassured that there were others who shared similar experiences and they were offered information on local support resources as well as official reporting channels and sources of authority, should they wish to disclose.

\subsection{Data Analysis}

Data analysis followed the principles of thematic analysis [12-14]. Thematic analysis involved systematic work based on the text to identify topics that are progressively integrated into higher order themes, via processes of de-contextualization and re-contextualization. A theme was a cluster of linked categories conveying similar meanings and emerged through the inductive analytic process which characterized the qualitative paradigm.

More specifically, the recorded discussions were transcribed verbatim and analyzed in the original language. Researchers from each country independently reviewed two transcripts each. The next step included code generation. Some of the codes were based on the questions asked during the interview and others arose from the emergent themes. The lead team was in charge of merging the four country codebooks into one. Overlapping codes were merged into one, and other emerging codes were incorporated into the codebook, as necessary. The codebook was tested with two transcripts per country. Inter-coder comparisons were carried out and differences in interpretations of code names and coding practices were discussed. The codebook was finalized when agreement was reached. Data coding was then conducted at country level and each site owned the country data. Transcripts were double coded at country levels to ensure consistency in coding.

Each team developed a narrative report in English using standardized headings to facilitate cross-country analysis. A comparative analysis of these reports was led by the Greek team (MP, NR) in close consultation with all the teams.

Consistency across the study sites was reassured through: (a) introducing a commonly agreed study protocol with standardised procedures, tools, and framework of cross-country analysis, (b) delivering joint training for individual teams on the study proto- 
col and objectives, (c) developing a codebook, (d) asking two researchers from each country to independently review transcripts and discuss any discrepancies with the lead team, (e) asking each team to discuss at team level all the new codes that emerged from the data.

\section{Results}

\subsection{Participants' Characteristics}

The demographic information of the participants is presented in Tables 1 and 2. A total of 66 female migrant domestic workers participated in the study (Austria $=15$, Cyprus $=16$, Greece $=20$, Sweden $=15$ ).

Table 1. Participants' profiles.

\begin{tabular}{|c|c|c|c|c|}
\hline & Greece $(n=20)$ & Austria $(n=15)$ & Cyprus $(n=16)$ & Sweden $(n=15)$ \\
\hline Age * & 40.1 & 37.2 & 37.1 & 36.0 \\
\hline \multicolumn{5}{|l|}{ Family status } \\
\hline Single & 2 & 14 & 5 & 6 \\
\hline Married & 10 & 1 & 5 & 7 \\
\hline Divorced & 4 & 0 & 3 & 2 \\
\hline Widow & 2 & 0 & 0 & 0 \\
\hline With partner & 1 & 0 & 2 & 0 \\
\hline Unknown & 1 & 0 & 1 & 0 \\
\hline \multicolumn{5}{|l|}{ Children } \\
\hline Yes & 15 & 1 & 10 & 9 \\
\hline No & 3 & 14 & 6 & 6 \\
\hline Unknown & 2 & 0 & 0 & 0 \\
\hline \multicolumn{5}{|l|}{ Educational level } \\
\hline Elementary & 8 & 0 & 2 & 0 \\
\hline Secondary & 5 & 2 & 2 & 0 \\
\hline Higher education & 3 & 10 & 4 & 1 \\
\hline Unknown & 4 & 2 & 8 & 14 \\
\hline Years in host country * & 13.9 & - & 3.5 & - \\
\hline Years in domestic work * & 9.3 & - & 3.8 & - \\
\hline \multicolumn{5}{|l|}{ Work situation } \\
\hline Full time & 16 & 1 & 10 & 0 \\
\hline Part time & 0 & 14 & 6 & 0 \\
\hline Unknown & 4 & 0 & 0 & 15 \\
\hline \multicolumn{5}{|l|}{ Social insurance } \\
\hline Yes & 5 & 0 & 10 & 1 \\
\hline No & 11 & 15 & 0 & 0 \\
\hline Unknown & 4 & 0 & 6 & 14 \\
\hline
\end{tabular}

${ }^{*}$ Average.

\subsection{Perpetrators' Profile}

In Greece, in all cases, perpetrators were male and in the majority of cases, the perpetrator was the employer himself, aged between 50 to 82 years. In some cases, the perpetrator was the son or the husband of the employer, usually aged between 30 to 55 years. In Cyprus, all the participants, except from two, identified the employers themselves as the perpetrators, while the rest were harassed by other people in the domestic environment. The vast majority of the perpetrators were men aged 60 years or more, widowers. In Austria, the social status and personal characteristics of the employer were not known, while in Sweden, the perpetrators were male service clients, i.e., all women were either self-employed or employed by a private company; the majority of them were unmarried or divorced and between the ages of 40-65 years. All perpetrators in Sweden could be viewed as well-established in the society, with an occupation and a steady income. 
Table 2. Participants' countries of origin.

\begin{tabular}{ccccc}
\hline & Greece $(\boldsymbol{n}=\mathbf{2 0})$ & Austria $(\boldsymbol{n = 1 5})$ & Cyprus $(\boldsymbol{n}=\mathbf{1 6})$ & Sweden $(\boldsymbol{n}=\mathbf{1 5})$ \\
\hline Country of origin & & & 0 & 0 \\
Albania & 8 & 0 & 0 & 0 \\
Bulgaria & 5 & 2 & 0 & 0 \\
Romania & 2 & 0 & 0 & 0 \\
Germany & 2 & 0 & 14 & 1 \\
Philippines & 1 & 0 & 0 & 0 \\
Georgia & 1 & 0 & 0 & 0 \\
Moldavia & 1 & 0 & 2 & 0 \\
Sri Lanka & 0 & 0 & 0 & 0 \\
Hungary & 0 & 1 & 0 & 0 \\
Ukraine & 0 & 7 & 0 & 1 \\
Peruvian & 0 & 0 & 0 & 0 \\
Slovakia & 0 & 1 & 0 & 0 \\
Serbian & 0 & 1 & 0 & 0 \\
Ethiopia & 0 & 1 & 0 & 1 \\
Russia & 0 & 2 & 0 & 1 \\
Bolivia & 0 & 0 & 0 & 1 \\
Ecuador & 0 & 0 & 0 & 1 \\
Eritrea & 0 & 0 & 0 & 1 \\
Estonia & 0 & 0 & 0 & 3 \\
Latvia & 0 & 0 & 0 & 1 \\
Poland & 0 & 0 & 0 & 2 \\
Somalia & 0 & 0 & 0 & \\
Thailand & 0 & 0 & 16 & \\
Total number & 20 & & & 15 \\
\hline
\end{tabular}

\subsection{Domestic Work: An Unintended but Inevitable Work Option for Female Migrants}

Domestic work was shown in all the countries not to be a first choice for female migrants, except from Cyprus, where all the participants came to the country to work exclusively as domestic workers. In particular, a network of collaborating employment agencies between Cyprus and various countries enabled the recruitment and transfer of women for employment purposes. In Austria, Greece, and Sweden, the vast majority of the participants worked as domestic workers either due to the lack of local language skills or due to the low educational attainment and the lack of qualifications. Qualified participants in these countries reported being obliged to work as domestic workers due to their undocumented or irregular status, which did not allow for official employment at a position corresponding to their qualification. Many of the participants in these countries described domestic services as, almost, the only way into the labour market for migrant women, especially those with irregular status. In Austria, the participants were not allowed to exceed the marginal employment threshold, which was much too low to make a living, so they had to work illegally. Besides that, participants in Austria felt most secure from the police and their activity against illegal migration, when working in the domestic sector as compared with other employment positions.

"I work with house cleaning since I have to support myself. To get another job, it requires that you can speak very good Swedish and I can't; therefore, I work in domestic services."

(DW, Sweden)

\subsection{Unsafe Job Inquiry through Informal Sources or Third-Persons' Arrangements}

Various channels were employed by migrant women in terms of job inquiry in the country of destination. In Greece, for example, the majority of the participants located this employment post either through relatives and friends or through advertisements in local newspapers, while in Austria, this happened through advertisement via the internet, which is the most common way in Austria for a migrant to find a job as a domestic worker. Interestingly, in Austria the attraction of new clients was shown in many cases to be 
proportional to the "positive" personal traits of the employee. One participant from Austria explained that when she placed an ad focusing on her working skills (technical details), she received very few calls. However, when the ad was focused on her personal traits, like being "nice", "cheerful", and "caring", this rendered a greater response. The participant's own reflection was that the focus on personal traits could be misleading due to resembling those of partner/spouse search. In Sweden, women worked as freelancers and received phone calls by the clients upon advertising their business in newspapers. A different model was found in Cyprus, where all the participants were recruited by employment agencies operating in their countries of origin and were linked to potential employers in the host country by employment agencies. Agencies presented the participants with various employment opportunities in the host country and provided them with information on potential employers' profiles and their individual and family background and economic status. Potential employers were praised by agencies for being wealthy and therefore "a good family".

"I would like to show you a text message. I could just understand half of it so I asked my husband ... I will show you ... : "Hi, saw your ad. Do you sell 6? If so, text me. Johan."

(DW, Sweden)

\subsection{Entrapment in an Unregulated Work Environment with Unfair Working Conditions}

The law provisions regarding payment and social insurance of domestic workers were not followed for the majority of the participants, regardless of their legal status. In all the countries except from Cyprus, most of the participants worked unofficially with their working conditions being negotiated and regulated by a verbal agreement between the employer and themselves. Participants in these countries worked primarily on a morning to evening shift or a part-time employment involving few hours per day for few days a week. In Greece, even those few, who had an official employment contract, worked full time and often overtime, despite having a part-time contract. In Austria on the other hand, for all the participants, the employment was informal, part-time, low-paid, while none of them had social insurance. In Sweden, the domestic service sector structure was made up by a few large companies and the majority of participants were self-employed. The work demand was reported to be customer-driven, i.e., that work had to be performed when it was suitable for the service buyers. This resulted in an uneven work load that usually included work on weekends and bank holidays. Participants referred to an uneven power balance between themselves and the service clients, exacerbated by their foreign origin and their low local language skills, which in turn resulted in the participants' inability to defend themselves in potential conflicting situations regarding work duties and their giving in to the clients' demands. In Sweden, participants also reported being pressured to accept a combination of both formal and informal wages, while many of them referred to the "trial employment", a special feature of the domestic service industry in Sweden, which can be viewed as a way to exploit labour for free. Eight (8) of the participants reported being forced to work without pay, some several times, without this rendering a formal contract.

In contrast with the other countries, in Cyprus, for the majority of the participants, domestic work was a formal job with social insurance included. The majority of participants had a full-time formal contract agreement with their employer, with live-in arrangements and had their own room within the employer's house. The employment conditions were presented by the agencies as very favorable, with the contractual duties involving domestic work for only one employer in one house, $7-8 \mathrm{~h}$ of work per day, compensation for overtime work, and one day off per week. Despite the signed contract already in place and the excellent references for the employers provided by the employment agencies, the reality was very different for all the participants, with their duties involving responsibility for more than one household, more than 12-h employment per day, and working at least half a day on their day-off without extra pay. As for the work duties, most of the participants 
in Greece and Cyprus were assigned the tasks of elderly care and housekeeping, while in Austria women were often assigned with housekeeping and babysitting.

"It was not an official work, it was not legal at the time, I had no insurance because we did not have a residence permit."

(DW, Greece)

\subsection{Escalating Harassment: From Masked Kindness to Sense of Possession}

In all the cases, violence/harassment occurred when the employer was alone in the house with the employee. In a few of the cases, sexually-oriented advances were made even when the employer's children were at home. In Greece, two participants were raped while set unconscious, realizing their victimization months later, in the presence of unexplained gynecological problems and unwanted pregnancy. Most incidents occurred at home, while few of them occurred in the employer's car. Some participants, including but not limited to the victims of rape, experienced single incidents mainly due to the victim's abandonment of their work immediately after the incident. For example, in Sweden and Austria, most of the participants were harassed upon their arrival at the employer's house and there was no opportunity to familiarize themselves with their employer.

"He opened the door barefoot and in a bath robe. [ . . . I I entered the room and there was already a champagne bottle on the desk. I said: 'I don't want champagne.' He started talking about his shoe shop and that I could work there. He also told me that I could work for his shop as a model. [ ... ] Then he told me that I should start with a massage and that he will pay me 20 euros for it."

(DW, Austria)

The participants experienced many different forms of sexual violence. The vast majority of them reported experiencing sexually-oriented advances, sexualised physical contact, and an offer of money for sex services. In Sweden, the majority of the participants reported receiving requests for sexual favours through the phone, being treated without respect and often being mistaken for offering sexual services instead of domestic services.

"I often get offered more money if I am willing to clean topless or without panties. Sometimes up to 500 SEK per hour. It is insane ... and insulting! I am not a whore, I am a mother!"

(DW, Sweden)

". . . he used to come close while I was washing the dishes, touching my body with his hands while I was ironing, he was touching my chest..."

(DW, Greece)

For the majority of the participants, sexual harassment escalated through time, started with staring and flattering, progressively becoming more pronounced such as unwanted touching that made the participants feel uncomfortable and eventually involved coercive kissing and efforts of seduction accompanied with an intimidating behaviour towards the victim. In Sweden, kindness was a common characteristic of potential clients that was misleading and kept their real intention hidden. The relationship with male clients often resembled that of a partner/wife and placed the man/client emotionally above the woman. In this unequal relationship, the language barrier became a significant problem, which frustrated participants as they could not explain their feelings to the clients' native language when sexual harassment occurred. 
"There was this really nice man, divorced with grown up children. I had cleaned his house for about seven times and he was always so nice ... /pause/ ... I almost became interested. But then one time, when I doing the dishes, he came up from behind and suddenly put his hands on my breasts and whispered 'Do you want to take a break?' I turned around and pushed him away. For a long time, I felt responsible ... /pause/... maybe I had encouraged him in some way."

(DW, Sweden)

\subsection{Initial Reactions: Tricky Relationships and Stay or Go Decisions}

Many participants, especially in Austria, resigned as soon as the harassment started. In some cases, the employers' intention to buy sexual services was disclosed from the first moments of job assignment, causing the direct resignation of the participants. Likewise, many participants from Greece chose not to disclose their victimization and left the job immediately without alternative job arrangements in place.

"I quit this job without indicating the real reason for this decision. I found some excuses to tell his wife, such as that I had been tired, that the house was very big, that I had found something closer to my house."

(DW3, Greece)

In Austria, one participant, despite feeling uncomfortable with her employer's behaviour, could not distinguish at the beginning whether she was sexually harassed by her employer or whether this behaviour was part of "making fun" due to her poor language capabilities. She was afraid that her employer would not pay her, therefore she stayed and continued being friendly, although she was scared of him.

Many other participants decided to keep the job and cope with the situation for as long as possible without disclosing their victimization, hoping that the situation would be temporary or at least until another job with minimum requirements was in place. Women in these cases decided to disclose when they understood that these advances would not stop and that their safety was at risk. This was especially true for Greece and Cyprus. In Greece, for example, the participants remained at the specific work position for approximately 3 months to 2 years after the first incidents of sexual harassment. In Cyprus, participants tried discretely to show to the perpetrator that their actions were not acceptable through their stance, keeping their distance and avoiding being alone with the perpetrator, or even wearing unattractive clothes which were dirty in order to make themselves less appealing.

"I want to shout but I don't know why I cannot shout, I want to ask for help but I can't because I'm really scared, I don't know what to do. [ ... I I want to protect myself but I'm just lying there."

\section{(DW, Cyprus)}

In Austria, some of those who remained at their post longer did not even feel safe to drink anything they offered to them, out of fear that they would sedate them, while others found various ways to protect themselves and feel safer during the incidents, such as by pretending to have a husband who was waiting for them.

"I am not married, but I said that I am married and that my husband knows where I am.

[... ] I needed to act. I knew that this might or might not work, but this bad man needed to know that I have a husband. After that he went away. Of course I was afraid, but that's psychology."

(DW, Austria)

The majority of those who disclosed the incidents at an early stage turned to their husbands and family network, especially in the case of Greece. When their husbands/partners learned about the incident, resignation was immediate. On the contrary, some women in Sweden chose to not tell their parents about the incidents in order to protect them from worrying. 
"My parents did not know. I told them a few years ago, when I was stronger, because I didn't want to make them sad or didn't want them to think: ' $C$, what are you doing, come back home' ... so ... I kind of wanted to prove that I was strong and could take care of myself and I didn' $t$ want to bother them."

(DW, Sweden)

"Eventually I spoke to my husband because I could not bear with it anymore."

(DW, Greece)

Many participants informed the employers' family about the incidents of sexual harassment in an attempt to protect themselves, to keep their jobs, or offer plausible explanations for resigning. This was particularly true for Greece. In some of these cases, employers' family expressed sympathy and tried to deter domestic workers from abandoning the job, while in other instances, despite acknowledging the harm, the employer's family chose to let her go to safeguard the family's reputation. But in most of the cases, the employers' relatives did not accept the responsibility and demanded participants to resign. For one participant in Cyprus, who was raped, disclosing the assault to the family of the employer resulted in being asked by them to keep silence. The daughter of her employer did not believe her story and only after persistently asking her to allow access to medical care, she was accompanied by her to the doctors offering her own explanations about the incident. Some employers even placed blames of ingratitude on the participants for raising complaints after everything they had done for them.

(The perpetrator's) daughter came into the house and said "are you ok?" [ . . ] and then I told her the story of what happened of what her father did to me, and then she said "is that really true?" [ ... ] and then after five days [ ... ] put the lock on my room, on the toilet, on my washing room, and then they said to me, "don't tell it to your agent" [ ... ] (the daughter) saw me I'm fixing my things, "what's that?" [ . . ] "are you leaving? Are you going to do that to us? We even let you go to the doctor, to check you up to give you medicine, you will do that to us?"

(DW, Cyprus)

Despite that, in Cyprus, some participants depicted a protective attitude towards their female employers and their families, wanting to protect them from the "family dishonour" or avoiding causing tension between the couple. As a result, many of them appeared to be caught in situations of double psychological pressure: on one hand, wanting to escape the subjected sexual violence and on the other, wanting to protect the family life of their employers.

Few participants chose to confront the employers themselves and discretely stop this harassment. In Sweden, participants, despite feeling extremely uncomfortable and emotionally exhausted, tried gently to explain that unwelcome sexual approaches are viewed as insulting and offensive. In Cyprus, some participants informed their employers that they intended to inform their wives if they did not stop. Most of the employers never acknowledged the wrongdoing in the action when notified, while some of them apologized and promised that it would not happen again. Some put the blame on the participants, indicating that they were provoked by their beauty and young age. In many cases, the employers threatened the participants that they would lose their job if they did not respond and this was very common in Greece. In Cyprus, many participants felt an attitude of ownership by their employers towards them while their employers' wives and daughters were reflected in the narratives as passive spectators to their sexual harassment.

\subsection{Breaking the Silence: Sense of Safety and Barriers of Help Seeking}

None of the participants made a formal complaint to any authority or organization in Austria and Sweden, and none of them sought professional help after the incidents, neither psychological nor help from women's organisations/shelters. Likewise, it took a long time for some participants in Greece and Cyprus before they managed to reach an authority on that purpose. 
Reporting the incident for the participants in all countries was perceived as a risk to their job or feared that it might result in deportation or would threaten their livelihood and that of their families.

"(I) don't do anything because (I was) always thinking of (my) debt in Philippines so (I) can't be unemployed."

(DW, Cyprus)

"I couldn't make a police report the first time ... they would have sent me back to my home country. I didn 't have a residence permit, so it was my own fault, one could say."

(DW, Sweden)

"I don't do anything because I cannot be unemployed...fear of losing my job, I have two kids."

(DW, Cyprus)

In Cyprus, the majority of participants contacted their recruitment agencies in order to change their employer or alternative employment agencies to seek for new employer. Then they contacted the embassy, the labour inspectorate, and NGOs for help with the legal route. Running away and finding refuge in the Social Centre was the final stage of the journey for the majority of participants.

Some participants in Cyprus and Sweden turned to church either to pray or to seek accommodation. In Cyprus, although women sought accommodation in church, they did not ask help from a priest. These women were involved in church organisations in their own country of origin from where they were given contact details of the Catholic Church in Cyprus before their arrival.

"I could handle the situation by myself. When I was really sad, I went to the church and prayed and said to myself 'It will be all right'."

(DW, Sweden)

Loss of trust to authorities was evident among participants in all the countries. They did not view the police as encouraging them to seek for justice or claim their rights. Participants in Cyprus reported that they did not expect to get justice in Cyprus, as, on one hand, they were not believed, and on the other, they were viewed by officers as foreigners and promiscuous. Most participants thought that they would not receive any help by the Cypriot agents and that their story would be turned against them, as, on one hand, they were viewed as foreigners, and on the other, they viewed the Cypriot agents as friends of their employers. Similar views were reported by the participants in Sweden and Austria.

"I 'm sure that no one would have believed me. It was my word against his."

(DW, Sweden)

"The fact of being a foreigner is the main reason why I did not seek any help...you do not seek any help when you are a foreigner."

(DW, Austria)

"I don't believe that I should have reported it. I would not find justice."

(DW7, Greece)

The lack of friendly procedures and empathy by officers deterred many participants from reporting the incidents to the police in Cyprus. Some participants were disappointed by the long delays in the police department, their disbelief, and unwillingness to record sexual harassment without tangible evidence. In some cases, the police officers placed threats for punishment and persecution if the women were lying. One participant from Cyprus even reported that police officers started laughing when she told them she wanted to make a complaint for sexual violence/harassment.

"Why did they laugh? Is sexual harassment funny?" 
Postponing of trials was also a reason that reduced motivation to report. The contact with the Labor Department was not helpful either, with women being asked tangible evidence of harassment in order to get a release paper from the Labour Department and find a new employer, while faced with the risk of becoming illegal in a short time period.

".. if a woman is not able to find a new employer within a month, then her visa runs out and she becomes illegal."

(DW, Cyprus)

Taking action and dealing with the situation was also hampered by the women's isolation in all the countries, in combination with the lack of access to resources and information. Especially in Cyprus, women were picked up at the airport by agents and were transferred to the houses of their employers, where they were bound to live by the terms of their contract. Women were allowed free time outside the home of the employer only on Sundays, which meant that during the first days or weeks, women did not have any contacts or sources of social support outside the house of the employer.

"It is because we are alone, unprotected, we do not have our family support, especially now that, okay, I'm alone. I don't I have a boyfriend to protect me."

(DW3, Greece)

"I feel very very helpless, really, especially at that time I don't know where to go, [ ... ] what happened to me, I found a wrong organisation! A Cypriot man, and he (is in charge of what he calls) a Philippines association in Cyprus [... ] He is the one who encouraged me to come to Nicosia, he said he will help me, [ . . . ] (but after contact with) the Philippines consulate, [ ... ] (they) told me why you went there? His organisation is not legal, go away from him, he will pursue you to be a prostitute".

(DW, Cyprus)

"There was no SOS line or something in internet, I didn't know where to turn ... I don't speak the Swedish language fluently."

(DW, Sweden)

Last but not least, the loss of confidence, anxiety, worries, and decreased productivity and focus were the reported accompanying factors that created the emotional-psychological conditions that disempowered and disoriented the victims. This was particularly evident in Sweden. The experience created a strong desire in victims to forget about this experience, rather than to live through it again by reporting it or discussing it with anyone.

"I did not want to say anything, because first of all, it's a disgrace, I was ashamed."

(DW4, Greece)

\subsection{The Day after: Emotional Breakdown and Financial Insecurity}

The majority of the participants in all the countries reported experiencing feelings of fear, anger, uncertainty, and insecurity at the time of their sexual victimization. In Sweden, many participants blamed themselves and were severely traumatized.

Upon escaping from the violent situation, the trauma remained in many of the participants. For a certain period of time, many of the participants suffered depression and psychosomatic symptoms, which also affected their relationship with their partners and families.

"The most difficult period was when I returned to my house. I had nightmares about the time spent at my employer's house... In my dreams, I used to see myself locking the door and him coming into my room with a spare key ... I was terrified ..." ".

(DW11, Greece)

"For four to five months, I didn't want to have any sexual relations with my husband. I didn't want him to touch me at all." 
In Cyprus, for all women, sexual harassment resulted in increasing levels of uncertainty about their future and how to handle the situation. Women who were raped appeared to be severely emotionally traumatized and were crying throughout the interview. In Cyprus, the participant who got pregnant reported having suicidal thoughts and limited emotional attachment to her baby. She said that she hated the baby and she wanted to die. This participant had been hit by a car few months after giving birth to her child and had spent one week in hospital. For one participant, sexual abuse resulted in gynecological problems most likely linked to sexually transmitted diseases.

"I try to get up every morning [ ... ] I cry to my husband, I want to go home [ ... ] every time I remember I'm out of my mind, I feel I hate the baby [ ... ] I don't know why it happened to me, so many women do bad things while I was 19 so focused on my work, why did it happen to me [ ... ] I think it would be better if I died because I can't accept what happened to me."

(DW7, Cyprus)

Some others expressed negative feelings for men in general as well as mistrust for people. One participant from Greece returned to an unwanted marriage while in need for protection and left the relationship again at the end of the crisis. In Austria, all the participants reported high levels of stress before meeting their employers even during the initial telephone contact with them. One participant in Sweden stated that, after one incident, she was afraid of walking alone in the dark, especially when crossing the subway.

"If this happened at my work, who knows what could happen on the street among strangers?"

(DW, Sweden)

Some of the women reported feelings of anxiety, especially when meeting with new clients. In Sweden, some of the women brought a colleague/friend with them the first time they met with a client, as a precaution when they were suspicious. Many of the women reported that they used the internet to check out any new clients before agreeing to meet them in order to be certain of whom they were meeting. Some of the participants mentioned that they did not accept clients calling from untraceable telephone numbers. Others reported that they had to change telephone numbers in order to get rid of persistent callers asking for sexual favours.

"If I am going to meet with a new client, I first gather all information I can. If a client calls from an untraceable number... I usually don 't, I won't risk it ... no, because it is weird ... many persons have untraceable numbers ... but if the persons says ... aaaah ... if they don 't want to state their address or if he is weird in any way, I say no ... I am not interested."

(DW, Sweden)

"When you have received as many dirty phone calls as I have, you learn to distinguish between serious clients and idiots. Within few seconds, I can understand where they are getting at, through our conversation. Sometimes I just say 'I 'm busy' and hang up!'

(DW, Sweden)

Most of the participants experienced economic difficulties due to intentional or unintentional unemployment. There were, however, many participants that had not been affected economically, primarily those who left the job after they found a new one. In Greece, some women chose to work in other sectors such as the agricultural sector, while some other participants remained unemployed due to their inability to recover from the psychological trauma and its consequences.

"I chose not to work as a domestic worker again and I started assisting my husband in agricultural tasks. I felt safer to work with my husband even though the nature of work was harder and the salary was low."

(DW6, Greece) 


\subsection{Survivors' Needs: Tackling Multiple Vulnerabilities}

With negligible regulation of domestic workplaces, the group of domestic workers is often faced with increased vulnerability to harassment. This is exacerbated by workers socioeconomic status, ethnicity, and language skills. In Sweden, the participants reported experiences of uneven power balance between themselves and the service clients, which is exacerbated by the fact that the domestic workers were foreign born and often did not know the Swedish language. Improving migrant domestic workers' educational level, gaining new skills, and learning the local language were some additional needs commonly reported by many participants in an attempt to improve their interaction with the local community and their communication with their employers at the workplace. One participant from Greece, holding a university degree, expressed the need to establish mechanisms for the prevention of qualification mismatch in job inquiry as well as the recognition of higher education degrees in the host country, which would give her the opportunity to get a different job.

"I would like to have a better education, yes, of course, I want to, but I can't; I must first learn the Greek language better."

(DW8, Greece)

The need to develop employment opportunities for the victimized migrant domestic workers was also reported by the majority of the participants. Some participants were confronted with long-term unemployment after leaving their job while others were trapped in this employment for a long period due to their difficulty in identifying new employment options. In Austria, all the participants identified the work permit as their main need. One participant thought that she would never have been in such a situation of harassment if she had had access to the regular labour market at that time.

"This type of employment will always be risky and I can't avoid this risk. There is no organisation that can protect me, if I have to go to a stranger to work as a cleaner."

(DW, Austria)

Other participants considered the development of safe systems for job inquiry as more important for them than any other institutional help. In fact, most of the participants in Austria continued to be dependent on web advertisements for job inquiry after their victimization and thus they considered online system protection, as necessary. Feedback from previous employers and warning flags were seen as important technical features and necessary system requirements. Likewise, in Sweden, the need to improve work advertising was seen as a pressing gap.

Another important issue for the participants was the access to information and the availability of governmental agencies offering guidance and promoting domestic workers' understanding of their obligations and rights at work. Many of them reported feeling rather confused with the legislation and the bureaucracy, which made them unsure as to the action they needed to take in order to remain in a regular status. Few women in Cyprus expressed their disappointment when they faced reality in Cyprus and how this did not meet the expectations created by employment agencies in their country of origin. For this reason, they reported the need for employment agencies to provide accurate information to women about what their job involved and about the potential dangers they might face in their employment.

"For me, the agency should say what is really going on here, they should not just fancy us about what Europe is, [ ... ] they should warn us to be careful with our own selves, especially with the old men, or if we are alone in our room, not to trust anyone or something like this, just to warn us, to make us alert. What to do, so that we won't be shocked, or if that thing will happen, we can protect ourselves, [ ... ] The agency in the Philippines should warn us, [ ... ] And if you ever have a problem like that, these are some of the organisations you can go to". 
Most importantly, the vast majority of the participants had no or false information about the supporting organizations operating in the host country and their mission and expressed their desire to make this information widely available to migrant populations. Sexual harassment occurred in most of the cases during the first few days or weeks of the participant's employment, and at that time, the woman had no time to establish social links or contacts to other individuals who might provide some support. Therefore, participants from Austria and Cyprus, expressed the need for information about contacts that might be able to provide some information about what to do in cases of sexual violence/harassment and support them in taking action.

"Also, these people who are abused, they are afraid also to report, you know, some of them [...]. They must know that there is a centre or there is a person who can help them because they don't know."

(DW, Cyprus)

In Cyprus, women mainly discussed their need for support in reporting sexual violence/harassment and acting upon the situation. This involves support on a number of levels, from emotional support to informational and finally practical support. Women reported experiencing severe emotional trauma and shock following instances of sexual violence/harassment and their first response after realising the severity of the situation involved the need to report this to a person who would believe them as well as help them.

"I also go to my agent, I informed him I just wanted to talk to him for one more time to know about my situation, maybe he can give me some advice [ ... ] I am very afraid [ .... I I don't know what to do, frightened, and he told me just go back to your employer, just go back and work, I just talked to him that's all and he told me, if you make a lie we are in a big problem and that time when I heard that word from his mouth, I think he's not believing me, $[\ldots]$, and I think agent receive money from the employer, they are together, so whatever I tell to him, even that is true, he doesn't believe me, because I am just a foreigner here".

(DW, Cyprus)

Many participants reported the need to feel safer when they report their experience to their authorities, mainly in terms of their residency and employment permit. This involves a more migrant-friendly attitude as well as a more migrant-friendly system that allows for the women's interests and rights to be safeguarded.

"I suggest for the police, for example, there is a complaint especially in domestic, be alert, be active, investigate, not to be blah blah blah, not to be like that. And instead of convincing us to be ... not to be strong, to pursue the case, they convince us just to stop the case because you will not win!"

(DW, Cyprus)

"First of all, we were in the country illegally. If the same thing was happening in my country, I would have complained. Yes, I could talk. Because I would have the power to denounce it and it would not affect me. If I denounced the harassment here, the first thing they would ask me for is my residence permit and work permit. I had neither the one nor the other. As a result, they would kick me out of the country without my being able to do anything."

(DW6, Greece)

\section{Discussion}

According to the results of the present study, the phenomenon of sexual harassment against female migrant domestic workers remains silent and is underreported. Findings reflect other European studies as well as with the United Nations report on "Rights of Migrant Domestic Workers in Europe" [5,11,15,16].

The study shows that the profile of the migrant women employed as domestic workers as well as the employment processes and procedures are different in Austria, Cyprus, 
Greece, and Sweden. Nevertheless, their victimization seems to follow a common pattern. One commonality that cuts across all participant countries is the gendered nature of sexual assaults committed against women employed in the domestic sector. In this respect, the surrounding gendered cultural assumptions that often legitimize unwanted sexual advances towards females [1] intersect with a number of other vulnerabilities, such as disadvantageous economic condition, labour exclusion, legal status, social isolation, poor social networks, and ethnic vulnerability, all of which are factors that can be labelled as social and cultural vulnerabilities. Indeed, there is no one single factor to account for violence exerted against women. Several complex and interconnected social and cultural factors have kept women particularly vulnerable to the violence directed at them. Among them, the lack of economic resources underpins women's vulnerability to violence and limits the power to escape [2]. Nevertheless, although numerous studies exist on violence against women, they do not focus on the phenomenon of sexual violence against migrant domestic workers and the contributing factors.

According to the present study, what seems to be important for the protection of those women is the development of a safe job inquiry system, enabling employers' evaluation as well as securing their working rights. The United Nations considers this issue of vital importance. The adequate protection of human rights of migrant domestic workers should be recognized, on an international as well as on a European level, as a major challenge and it needs to be taken on with the aim of guaranteeing these workers the full enjoyment of their human rights, regardless of their citizenship status [16]. State laws and policies are severely criticized for transforming migrant domestic workers into an underclass of workers through maintaining unequal employment rights and conditions between domestic workers and other employees $[5,11,15]$. This low protection of domestic workers rights is thought to deepen and reinforce their dependence on employers and increase their vulnerability to sexual victimization $[10,13]$.

The study claims that improving the migrants' legalization procedures in the host countries could reduce illegal work and increase reporting of sexual violence/harassment, since the risks of human rights abuses are particularly high for migrant domestic workers with irregular or undocumented migration status [16]. However, even migrant domestic workers whose migration and employment statuses are fully legal are usually in a less favorable position than the national workforce in terms of the protection of their rights [16]. Therefore, equal access to the regular labour market is of key importance in the prevention of sexual violence/harassment and can be enhanced through adjustment of corresponding migration and labour policies, skill building and language-learning programs, and through efforts to remove the existing perceptions of domestic work as heavily gendered and racialised. Social inclusion measures as the above mentioned could minimize linguistic and cultural barriers as well as social isolation.

Additionally, this study underlines that the sources of informational and practical support should be made more available to migrant domestic workers through links with migrant communities or other social groups that these women might have contact with. NGOs or public agencies which are active in the sector of violence against women should extend their activities on immigrant communities and make their services known. Additionally, the current findings clearly indicate the need for the development of anonymous, gender- and culturally-sensitive and user-friendly information web tools, or SOS lines, and providing access to legal and psychological support and working rights' resources.

It is also very important for women who are linked to employers through employment agencies to receive comprehensive induction programs in the country of origin or destination. These programmes should include training on sexual violence/harassment and labour rights as well as housekeeping skills, which seem to be the only concern of employment agencies at the moment. Clear information on employment rights, labour legislation, gender violence legislation, and common practices of reporting sexual violence/harassment with contact details of key organisations in the country of employment should be provided prior to or on arrival. 
Raising public awareness and promoting migrants' social inclusion is of key importance in addressing discrimination against migrants in the domestic sector. Additionally, the research shows that it is important to ensure that gender remains mainstreamed in all policies and campaigns that promote rights of migrants.

Moreover, at a policy level, the situation with sexual crimes against domestic workers is often exacerbated by the absence of adequate legislation that protects the victims and prevents these crimes. Specifically, in the case of Cyprus, sexual crimes against domestic workers, if not resulting in aggravated crimes or not perpetrated by strangers in the street, virtually fall outside of any legal frameworks. In this respect, the research results emphasise the urgent need to set up appropriate legal frameworks, among which are the Istanbul Convention on Violence against Women and the ILO Domestic Workers convention.

Likewise, labour inspection faces particular challenges since the workplace is protected by the right to inviolability of the home, and this undermines the ability to undertake routine inspections. Some countries are developing new inspection methods that can be undertaken without entering the household, such as reviewing contractual documents or interviewing domestic workers and employers at the door.

Conclusively, it seems that the challenges are many and no silver-bullet solution exists regarding sexual harassment. Policies that reduce the cost of formal employment through fiscal incentives, such as tax breaks or subsidies, are present in many countries in Europe and have shown positive impacts on formal employment as well as job creation, labour participation, and work-life balance. Country-level experience also indicates that simplification measures can help in reducing the required paperwork or decentralizing procedures for domestic workers. Information campaigns can act as an important first step towards promoting formal employment arrangements. Such campaigns have been carried out in countries around the world. Besides all these initiatives that could strengthen the role of domestic workers and reduce the occupational risks, there is plenty of room for social dialogue and advocacy and evidence-informed policy-making.

\section{Study Limitations}

There are certain limitations regarding this study that need to be acknowledged. Firstly, the qualitative nature of the study, the snowball sampling, and the small number of participants do not allow generalizability of the findings to the general population of female migrant domestic workers in these countries. Secondly, the eligibility criteria and the recruitment strategy have excluded certain subgroups of migrant domestic workers such as those lacking the skills to communicate in the local language or those not sufficiently integrated in local networks or agencies. Thirdly, the participants were drawn from one region of each country and thus the findings do not necessarily apply to migrant domestic workers occupied in other regions of these countries. Fourthly, the interview guide was not exhaustive. This implies that there may be certain areas of interest not adequately explored. Last but not least, we need to acknowledge the fact that the lack of interpreters during the interview process as well as the development of narrative reports in English as a result of translation from local languages may have caused loss of important information. To minimise the effect of translation, we anticipated the involvement of two individual researchers in each country with high skills or proficiency in the English language.

\section{Conclusions}

The current study described the experiences of sexually victimized female migrant domestic workers in four EU countries. It further gave an insight of the barriers faced by the victims in seeking help. In summary, we found that many of the victims were employed irregularly, in "atypical relationships" that did not follow the law provisions in terms of payment and social insurance. The vast majority of them worked as domestic workers due to the lack of language skills, the low educational level and the lack of qualifications, as well as due to the undocumented status, which did not allow official employment at a position corresponding to their qualification. Victims suffered a number 
of post victimisation consequences including depression and psychosomatic symptoms, high levels of stress, economic difficulties due to unemployment, negative feelings for men and mistrust for people. Despite the huge burden, they did not feel comfortable in reporting incidents of sexual violence to local authorities and many of them believed that they would not be believed and/or their case would not be taken seriously either because there were no witnesses or because they are migrants. Only few sought help from public organizations or NGOs and few left their job immediately after their victimization mainly due to financial insecurity.

Based on the findings of this study, it seems important to improve the working conditions surrounding domestic work and enhance the skills of female migrant domestic workers in dealing with sexual harassment. Raising awareness of this population could increase their knowledge on human rights and reduce discrimination based on employment and ethnicity. Last but not least, introducing migrant-friendly approaches and procedures is expected to improve the quality of victims' contact with the services and increase reporting and help seeking behaviours.

Author Contributions: Conceptualization, M.P. and J.C. (Joannes Chliaoutakis); methodology, M.P., B.H., C.K., K.L., M.S., J.C. (Josie Christodoulou), J.C. (Joannes Chliaoutakis) formal analysis, N.R., C.P.; investigation, L.P., B.H., Z.A., J.C. (Josie Christodoulou), A.K., J.L., A.Z.; writing—original draft preparation, M.P., N.R., J.C. (Joannes Chliaoutakis); writing—review and editing, All authors; project administration, J.C. (Joannes Chliaoutakis); funding acquisition, J.C. (Joannes Chliaoutakis) and M.P. All authors have read and agreed to the published version of the manuscript.

Funding: This research was funded by the European Commission under the DAPHNE III programme (JUST/2011/DAP/AG/3272).

Institutional Review Board Statement: Ethical review and approval was granted by institutional committees.

Informed Consent Statement: Informed consent was obtained from all subjects involved in the study.

Acknowledgments: The authors would like to thank all the women who participated in this study and shared with us their personal experiences.

Conflicts of Interest: The authors declared no potential conflicts of interest with respect to the research, authorship, and/or publication of this article.

\section{Appendix A}

Appendix A.1. Interview Guide

Note

This interview guide is mainly for consolidating and ensuring that all the necessary information will be collected, rather than a schema that must be followed strictly. The purpose is to allow all interviews to have a conversational style while focusing on the predetermined thematic areas, and, to allow flexibility on capturing any unexpected information.

The interview guide is a support for the interviewer. It describes the areas and topics the researcher should ask and what he or she wants to know. There is no need for the questions to be asked exactly according to the protocol and the same applies for the answers. It should be more of a conversational style of interview than a question-answer-ping-pong. The mutual understanding between the interviewer and the interviewee is very important if the interview is more a talk where the interviewee sets the order of the topics.

When dealing with a difficult and tabooed topics, it is helpful to begin questions with:

"I know that this is a difficult question, therefore please feel free to answer it-it is up to you, how detailed you answer", or: "May I ask you a question which might bother you yet it would be important for me to understand your situation ...".

- usually the interviewees agree to raise the question

In general, we should take into consideration that this interview deals with very sensitive and painful issues thus we have to be aware of the participants' feelings. 


\section{Appendix A.2. Introduction}

As an introduction to the interview we may say something like this, or something similar:

"You are here with me, because I want to talk about the unpleasant experience of sexual violence/harassment you have had, while you worked as a domestic worker. Your experience will help us to learn more about this hidden phenomenon and enable us to propose measures that will empower migrant domestic workers to confront such assaults and facilitate their demands of support in the post-victimization period. We understand that this interview might cause unpleasant and difficult feelings so please feel free to take a break at any point."

Appendix A.2.1. Thematic Area 1: Working Conditions

Could you talk to me about your experiences as a domestic worker in Greece/Cyprus/ Austria/Sweden/......

What we need to know

1. Decision to come to (the host country) and to work here.

2. Description of her overall experience of working as a domestic worker (how did she find this work position, type of duties, part-time or full time, public health and social insurance, formal or informal work, live with your employer or not, employers' treatment, satisfaction of the salary).

3. Apart from your personal experience, have you heard about other incidences of sexual violence/harassment against domestic workers from other women you know?

Appendix A.2.2. Thematic Area 2: Incident Related Information

You have had a very unpleasant experience. I understand that talking about it might

be painful but do you think you could give me a brief description of your experience?

What we need to know

1. If she wants to share with us who the perpetrator was.

2. When did it start, and how did it start (if more than one incident has happened, try to extract information on all the incidents).

3. Under which conditions it occurred (when nobody was in the house? In DW's private room?)

4. What was the form of violence (Sexual harassment? Verbal sexualized violence? Physical sexualized abuse? Touching? Lustful looking/observing? Etc.).

5. If it was a single or repeated incident.

6. At which stage of your employment did it occur (soon after the job was undertaken? After how long or how many years at work?).

7. If she believes that other family members were aware of what was happening/happened. If they reacted and how.

Appendix A.2.3. Thematic Area 3: Perpetrator's Socio-Demographic Characteristics

1. Could you tell us, if you know a few things about the perpetrator?

2. What we need to know

3. About his social status, his education and work position marital status etc.

4. Which were his arguments/reactions after the incident / after each incident.

5. If, for some reasons she is still working for the same employer, why is she doing that?

Appendix A.2.4. Thematic Area 4: Response to Violence (Reactions, Strategies, Service utilization, Help-Seeking Behaviors, Social Network, etc.)

Let us now talk about your reaction. What did you do right after the incident and what did you do later on?

What we need to know

1. What did she do and when? What was her immediate reaction? (Did she talk about the incident with someone? With whom and when? Did she ask for help? From whom or from where) 
2. If yes: why did she choose to seek help from these people? (Help from her family, her social networks or from authorities or NGO or professional union, or all the above)

3. Were there factors preventing her from asking for help? Which were these factors? (Fear of destroying marriage / relationship, loss of work, illegal migrant status, informal work etc.)

4. What kind of assistance did she receive? Were she satisfied with the assistance provided to her?

5. Did she report the incident to the police? Did the report lead to prosecution?

6. Was the case eventually examined at the labor department or in court? (or by other official authorities, depending on the system of each participant country) What was the authority's decision? What was this experience like? (Did she receive any assistance while the case was handled by the court?)

7. If no: Why not? (Fear of destroying marriage / relationship, loss of work, illegal migrant status, informal work etc.).

8. What did she do in the end?

Appendix A.2.5. Thematic Area 5: Consequences of Violence (Short and Long-Term Physical, Emotional, Social, Economic, Consequences on the Victim and other Family Members)

Now, if you don't mind, we want to talk about the most important thing, the consequences/impact/effects of this experience for you and in your personal and social life.

What we need to know

1. If she thinks that the incident affected her personal life, her marriage /relationship/family life.

2. If she thinks that there were consequences for other members of her family due to the incident/incidents (children, parents ... ).

3. If she thinks that the incident affected her social life in general.

4. If she thinks that there were economic consequences, or consequences in her work position due to the incident.

5. What is/was the most difficult aspect of having experienced sexualized violence/harassment in the work-place? (Her psychological situation, the loss of her work, the discussion with her family, the dealing with the authorities etc.).

6. What were her overall feelings soon after the incident and how does she feels today.

Appendix A.2.6. Thematic Area 6: Victims' Self-Reported Needs for Support

(Psychological, Judicial/Legal, Educational and Economical)

Could you tell me now, if this experience you have had, has raised any new needs for you?

What we need to know

1. If she thinks that she needed or still needs emotional or psychological support and from whom or from which organization.

2. If she thinks that after the incident new economic needs have been raised (in case she lost her job or she does not want to work as DW any more).

3. If she thinks that she needs further education to improve her qualifications for entering a better work position.

4. If she thinks that she needed or still needs support of a relevant organization or NGO for counseling, legal support, problems' management etc.

5. If she is satisfied with the services she has gotten up until today or if not, and in that case, why? 


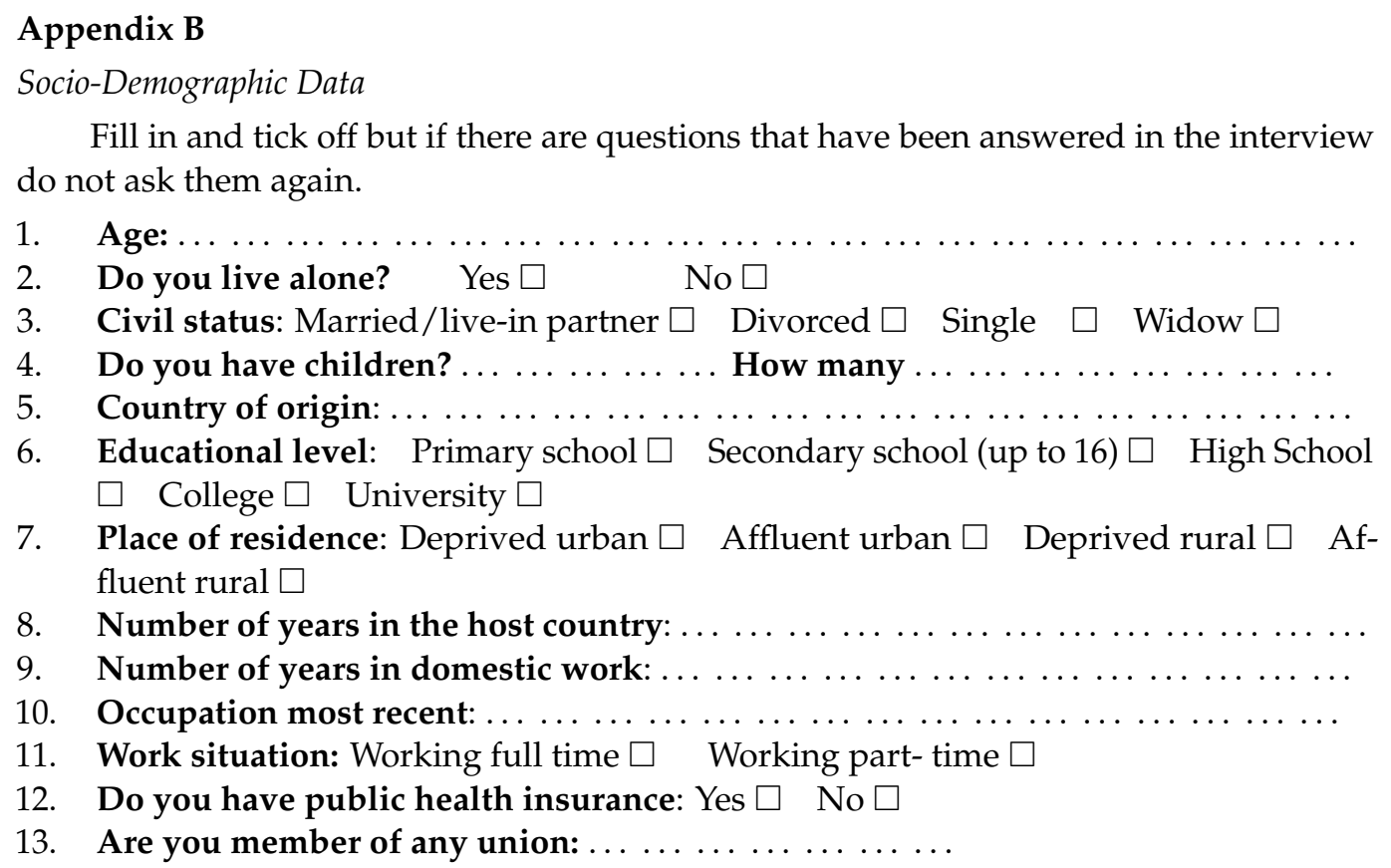

\section{References}

1. International Labour Office. Making Decent Work a Reality for Domestic Workers: Progress and Prospects Ten Years after the Adoption of the Domestic Workers Convention 2011 (No. 189); International Labour Office: Geneva, Switzerland, 2021.

2. Papadakaki, M.; Chliaoutakis, J. Sexual harassment against female migrant domestic workers. In WHO Public Health Aspects of Migration in Europe (PHAME Newsletter); World Health Organization: Geneva, Switzerland, 2016; pp. 10-11.

3. International Labour Office. Domestic Workers Across the World: Global and Regional Statistics and the Extent of Legal Protection; International Labour Office: Geneva, Switzerland, 2013.

4. Office of the United Nations High Commissioner for Human Rights. Behind Closed Doors: Protecting and Promoting the Human Rights of Migrant Domestic Workers in an Irregular Situation; Office of the United Nations High Commissioner for Human Rights: Geneva, Switzerland, 2015.

5. International Council on Human Rights Policy. Irregular Migration, Migrant Smuggling and Human Rights: Towards Coherence; International Council on Human Rights Policy: Geneva, Switzerland, 2010.

6. Gallotti, M. The Gender Dimension of Domestic Work in Western Europe; International Labour Office: Geneva, Switzerland, 2010.

7. Gavanas, A. Migrant domestic workers, social network strategies and informal markets for domestic services in Sweden. Women's Stud. Int. Forum 2013, 36, 54. [CrossRef]

8. Hadjipavlou, M. Cypriot Feminism: An Opportunity to Challenge Gender Inequalities and Promote Women's Rights and a Different Voice. Cyprus Rev. 2010, 22, 247-268.

9. Calleman, C. Arbetskraftsinvandring för arbete I private hushall. In Rena Hem på Smutsiga Villkor; Gavanas, A., Calleman, C., Eds.; Makadam: Stockholm, Sweden, 2013.

10. May, T. Social Research; Open University Press: Buckingham, PA, USA, 1993.

11. Council of Europe. Convention on Preventing and Combating Violence Against Women and Domestic Violence, Article 40; Council of Europe: Strasbourg, France, 2011.

12. Guest, G.; MacQueen, N. Introduction to Thematic Analysis. In Applied Thematic Analysis; SAGE: Thousand Oaks, CA, USA, 2012; p. 11.

13. Braun, V.; Clarke, V. Using thematic analysis in psychology. Qual. Res. Psychol. 2006, 3, 83. [CrossRef]

14. Miles, M.B. Qualitative Data Analysis: An Expanded Sourcebook; SAGE: Thousand Oaks, CA, USA, 1994.

15. Thomael, M.; Joannidis, X. Identity in Conflict: An Exploration of Gender across-Ethnicity in Cyprus. Cyprus Rev. 2012, 25, 109.

16. OHCHR's Regional Office for Europe. Rights of Domestic Workers in Europe; Regional Office for Europe: Brussels, Belgium, 2010. 